\title{
EFL LEARNERS' GRAMMAR KNOWLEDGE DEVELOPMENT THROUGH EXPLICIT AND IMPLICIT FEEDBACK: SOCIAL NETWORKS IN FOCUS
}

\author{
Samane Naderi \\ Corresponding Author, University of Applied Science and Technology, Iran, \\ samane.naderi61@gmail.com
}

\begin{abstract}
This study investigated the effect of explicit text based and implicit emoticons and emoji based feedback through social network on the EFL learners' grammar knowledge development. To fulfil this purpose, one control group and two experimental groups each consists of 20 learners were selected. The pre-test was conducted to evaluate learners' grammar knowledge. During the term, three types of verb in English were instructed in the classroom for all three groups in a same way. For two experimental groups two separate telegram groups were created in which the learners of one experimental group received explicit text-based feedback and the other group received implicit emoticons and emoji based feedback and the control group received no feedback on their grammar exercises' answers. At the end of the course, the posttest was administered to investigate the effect of two kinds of feedback. Finally, the interviews were conducted with 10 members of each experimental group. The results of the one-way ANOVA revealed that these two kinds of feedback had significant effect on the EFL learners' grammar knowledge development, also the superiority of the experimental group with explicit text-based feedback was found. The interviews' findings indicated that most of the learners preferred explicit text-based feedback.
\end{abstract}

Keywords: Explicit text-based feedback; Implicit emoticons and emoji based feedback; Emoticon, Emoji, Social networks; Grammar knowledge

\section{INTRODUCTION}

In the 21st century, using technology for pedagogical purposes has change into the main objective for many of the authorities of education. In the period of globalization, the modern technologies related to mobile and such kinds of devices contribute to rapid promotion of learning and teaching process (Yedla, 2013). In online learning provides the opportunities for learners to receive the feedback on assignments and tasks even without the synchronous contact with their teacher. Hence, it is essential for teachers to apply the appropriate and related kinds of feedback to make the learning process more efficient. Feedback is considered as a tool of increasing learners' awareness and retention in the online environment (Anderson, Imdieke and Standerford, 2011).

Availability of different social networks, applying them in learning and teaching processes and the importance of the different types of feedback in on-line learning settings made the researcher interested in the subject of using explicit text based and implicit emoticons and emoji based feedback in social network instruction on the EFL learners' grammar knowledge. The aim of this study is to investigate the effect of explicit text based and implicit emoticons and emoji based feedback in social network instruction on the EFL learners' grammar knowledge.

Citation: Naderi, S. (2018). EFL Learners' Grammar Knowledge Development through Explicit and Implicit Feedback: Social Networks in Focus. Anatolian Journal of Education, 3(1), 31-38. https://doi.org/10.29333/aje.2018.313a 


\section{Statement of the Problems}

In an educational environment, feedback is defined as any process and communication has been used to inform the student of his answer correctness (Sales, 1993). Appropriate feedback to learners in learning process is a crucial part of education since it can facilitate learning. In online learning, feedback is provided in the synchronic and asynchronic formats (Kowitz and Smith, 1987). Because of the differences between this kind of learning and traditional classroom including the physical separation of the teacher and learners, special kinds of feedback are applicable (Keegan, 1990).

\section{Significance of The Study}

Feedback is a fundamental element in online learnings and can improve the learner's process of learning, and according to Perrin (1999) "feedback goes beyond confirmation of correct answers (behaviorism) to develop new understandings and structures to facilitate learning (constructivism)" ( $p$. 1). Due to the significance of feedback in online learning settings, this study can provide a number of suggestions for teachers, syllabus designers and learners who are interested in this type of learning in order to increase on-line feedback effectiveness.

\section{Literature Review}

\section{Feedback}

The learners' learning ability can be developed by feedback (Bitchener, 2008). According to him, teacher's feedback can be considered as a major component which contributes the learners to fill the gaps in learning process. Ashwell (2000) believes that feedback is the response that a learner receives for his performance from teacher and classmates. Moreover, corrective feedback can beneficial for learners to get the meaning and to enhance their skills. Feedback is defined in different situations, sometimes, it refers to the teacher's response following the errors of a learner for making the learner aware of the errors directly and indirectly (Chaudron, 1988).

\section{Text Based Feedback}

In this kind of feedback, the correct form is provided explicitly in written form. The teacher obviously shows the learners' error and points out the correct form trough writing (Lyster and Ranta, 1997).

\section{Implicit Emoticons and Emoji Based Feedback}

This type of feedback can be used to express social emotional information and to strengthen the meaning of a message (Derks, Bos and Von Grumbkow, 2008b).

Emoticons can be used as a kind of on-line feedback. It is short form of emotion icons. In fact, they are ways to represent emotional, personal feelings and the nonverbal behaviors and cues which can be demonstrated in face-to-face interaction. Examples of Emoticon:

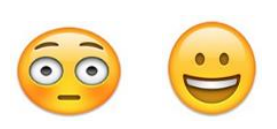

According to Merriam-Webster dictionary, emoji is "any of various small images, symbols, or icons used in text fields in electronic communication (as in text messages, e-mail, and social media) to 
express the emotional attitude of the writer, convey information succinctly, communicate a message playfully without using words, etc."

Examples of emoji:

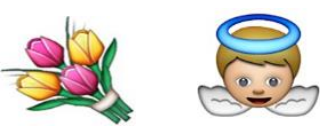

\section{Social Network Instruction}

Social network instruction can facilitate communication, interaction, and cooperation, so it is important in the discussions pointing out the applying of technology to support instructional efforts (Greenhow, Robelia, and Hughes, 2009).

\section{METHOD}

\section{Research Design}

Mixed method of quantitative and qualitative methods was applied for this study. First, the quantitative data was collected by the pretest and posttest and analyzed through One- Way ANOVA test. Then the qualitative data which was collected through the interviews was analyzed and interpreted by the researchers.

\section{Participants}

For this study 60 intermediate EFL learners were selected out of 72 intermediate EFL learners by the use of a placement test. Then they were divided into three groups. One control group and two experimental groups each consists of 20 learners. Their age varied from 18 to 45 and their educational levels were different from high school to master degree. To control the effect of the gender these learners were selected just from the female learners.

\section{Data Collection Instrumentations}

\section{Proficiency test.}

To homogenize the learners' proficiency level, the placement test (Lesly, Hasen \& Zukowski, 2005) was utilized. This test is a multiple choice evaluation package consists of 70 items, including listening (20), reading (20) and language use (30). The achieved scores were placed based on the proficiency guidelines. According to the guidelines, the scores between 37 and 49 were categorized as the intermediate level.

\section{Researcher-made Pre-test}

To investigate the pre-existing differences in grammar knowledge among participants, some exercises in the domains of 3 types of verbs in English (simple past, present prefect and past prefect) were selected and applied as the pre-test. This test includes multiple choice items, cloze test and substitution items. The test was piloted among 20 intermediate EFL learners and its reliability was calculated via Cronbach's Alpha which was .714. In addition, its content validity was confirmed by three related experts. 


\section{Researcher-made Post-test}

To test the hypotheses of the study the researcher again selected some other exercises in the domains of 3 types of verbs in English (simple past, present prefect and past prefect) and used as the pre-test. This test also includes multiple choice items, cloze test and substitution items. This posttest was piloted among 20 intermediate EFL learners too and its reliability via Cronbach's Alpha was .746. Also, its content validity was confirmed by three related experts.

\section{Open ended interview}

This open ended interview consists of two questions to investigate:

1. EFL learners' ideas about these two types of feedback

2. Their preferences between these two types of feedback

\section{Procedure}

As previously mentioned, to determine the homogeneity of the participants, the placement and evaluation package of the interchange book (3rd Edition) was used; then, according to the test results, the subjects who achieved the intermediate scores were chosen as the study participants, those who had scored between 37 and 49 out of 70. Consequently, 60 intermediate EFL learners were selected out of 72 ones and randomly divided into three groups of intermediate EFL learners. One control group and two experimental groups each consists of 20 learners. The researcher-made pre-test was conducted to evaluate learners' grammar knowledge before the treatment. During the term (20 sessions), three types of verb in English (simple past, present prefect and past prefect) were instructed in the classroom for all three groups in a same way. Some grammar exercises were appointed to be done by the learners at home. For two experimental groups two separate telegram groups were created in which the learners received feedback on their grammar exercises' answers. One of the experimental group received explicit text-based feedback by the use of merely text and the other group received implicit emoticons and emoji based feedback without using any texts just from the teacher as the treatments of the study and the control group received no feedback on their grammar exercises' answers. In the class, none of them received any kinds of feedback on their grammar exercises' answers and all learners should come to the class with the correct answers next session. Finally, the interviews were conducted with 10 members of each experimental group to find their ideas about these two types of feedback. At the end of the course, the researcher-made posttest was administered to investigate the effect of two kinds of on-line feedback on the intermediate EFL learners' grammar knowledge.

\section{Data Analysis}

To analyze the quantitative data in this study, the Statistical Package for Social Sciences (SPSS), version 19, was utilized. The level of significance was set at .05 . The first phase of the data analysis was investigating the reliabilities of researcher-made pretest and posttest via Cronbach's Alpha. Then, the subjects' level of proficiency was evaluated by the use a placement test. The pretest scores were analyzed by ANOVA test to investigate the differences among three groups participants' grammar knowledge before the treatments. Descriptive statistics of the pretest and posttest scores were investigated through SPSS. Finally, to see whether two kinds of feedback had significant effect on the learners' grammar knowledge development or not, again ANOVA test applied to the posttest scores of the all three groups. 


\section{FINDINGS}

To fulfill the purpose of study, following statistical procedures were applied to the collected data. Table 1 shows the descriptive statistics of the experimental and control groups in grammar knowledge at the pretest and posttest.

Table 1

Descriptive Statistics of the Experimental and Control Groups in grammar knowledge at the Pre-Test and Posttest.

\begin{tabular}{|c|c|c|c|c|c|c|c|}
\hline \multirow{4}{*}{$\begin{array}{l}\text { Pretest } \\
\text { grammar } \\
\text { knowledge }\end{array}$} & Explicit & $\begin{array}{l}\mathrm{N} \\
20\end{array}$ & $\begin{array}{l}\text { Mean } \\
1530\end{array}$ & $\begin{array}{l}\text { Std. } \\
\text { Deviation } \\
3.74\end{array}$ & $\begin{array}{l}\text { Std. } \\
\text { Error } \\
817\end{array}$ & Min & $2^{M a x}$ \\
\hline & & & & & & & \\
\hline & implicit & 20 & 14.95 & 3.74 & .838 & 7 & 21 \\
\hline & Control & 20 & 14.70 & 3.93 & .879 & 6 & 20 \\
\hline \multirow{3}{*}{$\begin{array}{l}\text { Post-test } \\
\text { grammar } \\
\text { knowledge }\end{array}$} & Explicit & 20 & 22.90 & 3.127 & .817 & 14 & 28 \\
\hline & implicit & 20 & 21.15 & 4.246 & .838 & 13 & 28 \\
\hline & Control & 20 & 16.90 & 3.93 & 3.768 & 10 & 25 \\
\hline
\end{tabular}

To ensure the normality of the scores' distribution, Kolmogorov-Smirnov test was conducted to the pretest and posttest scores and the results was displayed in table 2 .

Table 2

Test of Normality for the Experimental and Control Groups in Grammar Knowledge at the Pretest, Posttest and Gain Scores

\begin{tabular}{lllll}
\hline & & \multicolumn{2}{l}{ Kolmogorov-Smirnov $^{\mathrm{a}}$} \\
\cline { 3 - 5 } & group & Statistic & $\mathrm{df}$ & Sig. \\
\hline pretest & explicit & .101 & 20 & $.200^{*}$ \\
& & .217 & 20 & .014 \\
& implicit & .149 & 20 & $.200^{*}$ \\
\hline posttest & control & .093 & 20 & $.200^{*}$ \\
& explicit & .172 & 20 & .124 \\
& implicit & .165 & 20 & .158 \\
\hline
\end{tabular}

As it is indicated in the table 1 the distributions of the scores in pretest, posttest, and gain scores were normal; therefore, the parametric tests were used for analyzing the related data.

To investigate whether there are any significant differences in grammar knowledge of the three groups' learners and whether they were selected appropriately for the study, one-way ANOVA test was applied. The F-observed value and p-value were .127 and .881 , respectively. This amount of $\mathrm{F}$-value at 2 and 57 degrees of freedom was lower than the critical value of $\mathrm{F}$ and $\mathrm{p}$-value was higher than the significance level of .05 (see Table 2). 
Table 3

One-Way ANOVA on the Three Groups at the grammar knowledge pretest.

\begin{tabular}{llllll}
\hline & Sum of Squares & df & Mean Square & F & Sig. \\
\hline Between Groups & 3.633 & 2 & 1.817 & .127 & .881 \\
Within Groups & 815.350 & 57 & 14.304 & & \\
\hline Total & 818.983 & 59 & & &
\end{tabular}

Hence, it was found that there was no significant difference between the mean scores of the three groups at the pre-test $(\mathrm{F}(2,57)=.127, \mathrm{p}>.05)$ and these groups are optimal for the study.

To find out whether the feedbacks caused any differences, the mean scores of the three groups at the post-test were compared by the use of a one-way ANOVA. The F-observed value and p-value were 13.599 and 0.000 respectively. This amount of F-value at 2 and 57 degrees of freedom higher than the critical value of $\mathrm{F}$, and p-value was lower than the significance level of $.05(\mathrm{~F}(2,57)=$ $13.599, \mathrm{p}<.05)$.

Table 4

One-Way ANOVA on the Three Groups at Post-Test.

\begin{tabular}{lcllll}
\hline & Sum of Squares & df & Mean Square & F & Sig. \\
\hline Between Groups & 380.833 & 2 & 190.417 & 13.599 & .000 \\
Within Groups & 798.150 & 57 & 14.003 & & \\
\hline Total & 1178.983 & 59 & & & \\
\hline
\end{tabular}

Therefore, it was found that there is a significant difference between the mean scores of the three groups on post-test. The effect size, calculated via eta squared, was found to be 0.45 . This figure shows the degree of association between the dependent (post-test scores) and independent (two types of CF) variable, which is a large size (Dornyei, 2007).

According to the results of One-Way ANOVA, there is a difference among the means, but its exact place was not determined. To show the precise place of differences, a post hoc comparison of the means was used, So a Scheffe's test was applied and the results revealed that there was significant difference between all three groups of Control, explicit text based and implicit emoticons and emojis based feedback at the level of 0.05 (see Table 4 ).

Table 5

Scheffe's Test for the Comparison of Post-Test Means of the Three Groups

\begin{tabular}{|c|c|c|c|c|c|c|}
\hline \multirow[b]{2}{*}{ (I) group } & \multirow[b]{2}{*}{ (J) group } & \multirow[b]{2}{*}{ Mean Difference (I-J) } & \multirow[b]{2}{*}{ Std. Error } & \multirow[b]{2}{*}{ Sig. } & \multicolumn{2}{|c|}{ 95\% Confidence Interval } \\
\hline & & & & & Lower Bound & Upper Bound \\
\hline \multirow[t]{2}{*}{ implicit } & explicit & -1.75000 & 1.18333 & .342 & -4.7243 & 1.2243 \\
\hline & control & $4.25000^{*}$ & 1.18333 & .003 & 1.2757 & 7.2243 \\
\hline \multirow[t]{2}{*}{ explicit } & implicit & 1.75000 & 1.18333 & .342 & -1.2243 & 4.7243 \\
\hline & control & $6.00000^{*}$ & 1.18333 & .000 & 3.0257 & 8.9743 \\
\hline \multirow[t]{2}{*}{ control } & explicit & $-4.25000^{*}$ & 1.18333 & .003 & -7.2243 & -1.2757 \\
\hline & implicit & $-6.00000^{*}$ & 1.18333 & .000 & -8.9743 & -3.0257 \\
\hline
\end{tabular}

*. The mean difference is significant at the 0.05 level. 
The means of explicit, implicit and control groups' scores are displayed in the figure 1 below.

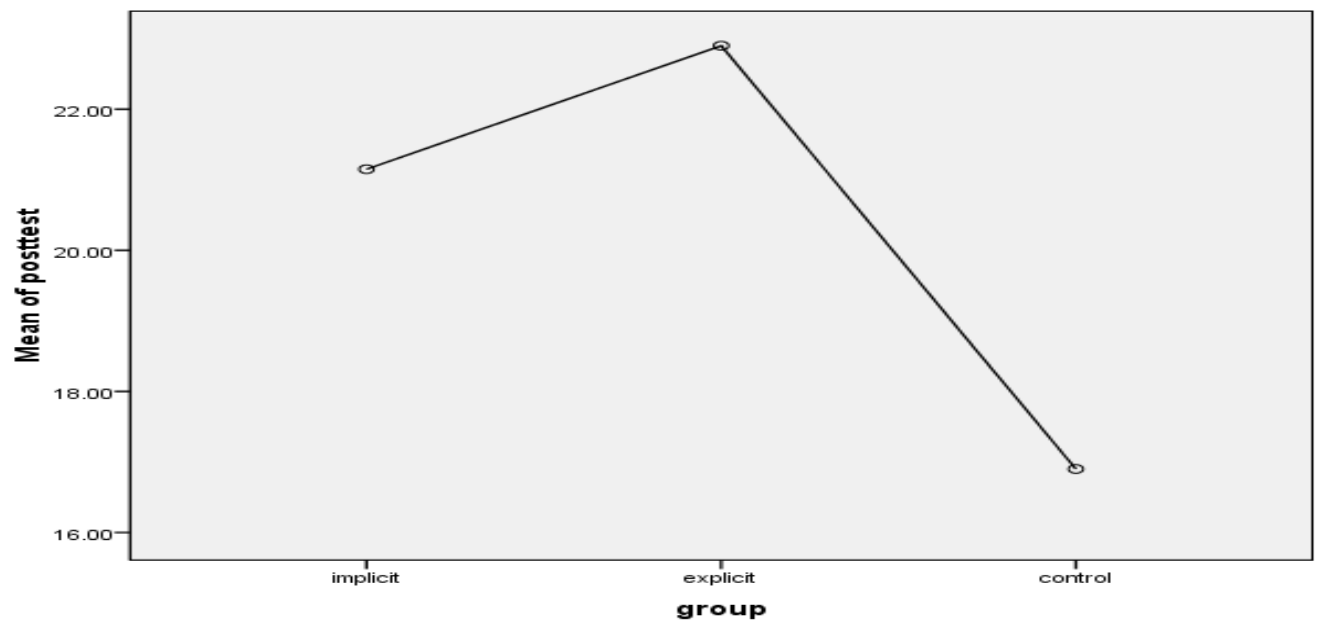

As the figure indicates, the mean of explicit group is higher than implicit and control ones. Also it can be concluded from table 1 and 5. We can find that explicit text-based feedback is significantly more advantageous over implicit emoticons and emoji based one in enhancing the learner's grammar knowledge development.

The results of the interviews with 20 learners of two experimental groups (from each group 10 members) revealed that most of the learners (13 learners out of 20) were not comfortable with implicit emoticons and emoji based feedbacks and they believed that in some situations using some emoticons and emoji can be confusing and the learners cannot recognize the teacher's addressed points. Also most of them (15 learners out of 20) preferred explicit text-based feedback in comparison with implicit emoticons and emoji based one; however, some of them believed that the implicit emoticons and emoji based feedback somehow made them to discover the answers by themselves.

\section{Discussion and Conclusion}

The purpose of this study was examining the effect of two types of explicit text-based feedback and implicit emoticons and emoji based feedback on the Intermediate EFL Learners' grammar knowledge development. Based on the achieved results of the one-way ANOVA and Scheffé post hoc tests it was found that both types of feedback were effective in EFL learners' grammar knowledge development; moreover, it was concluded that between two types of feedback, the explicit one was more effective than implicit one. The increasing availability to sophisticated, portable and affordable technologies over the recent years has provided a body of research into applying the technologies for instruction and learning in the formal and informal contexts (Stockwell and Hubbard, 2013). Recent attention to on-line learning requires the special ways of instruction and feedback. According to Chickering and Gamson, (1987), Feedback is necessary factor for good teaching and learning and also a primary element in online learning. Perrin (1999) claims that on-line interaction processes are enhanced through feedback because "feedback goes beyond confirmation of correct answers (behaviorism) to developing new understandings and structures to facilitate learning (constructivism)" (p. 1). It causes the flow of interaction between the members of a virtual group and it makes the online programs more 
effective. Therefore, the findings of this study can be beneficial for the leaners, teachers, material designers and teacher's trainers.

\section{REFERENCES}

Anderson, D., Imdieke, S., \& Standerford, N. S. (2011). Feedback please: Studying self in the online classroom. International Journal of Instruction, 4(1), 3-15

Ashwell, T. (2000).Patterns of teacher response to student writing in a multiple-draft composition classroom: Is content feedback followed by form feedback the best method?Journal of Second Language Writing, 9(3), 227-258.

Bitchener, J. (2008). Evidence in support of written corrective feedback. Journal of Second Language Writing, 7, $102-118$.

Chaudron, C. (1988). Second language classrooms: Research on teaching and learning.Cambridge, UK: Cambridge University Press.

Chickering, A. \& Gamson, Z. (1987) Seven Principles for Good Practice in Undergraduate Education. AAHE Bulletin, 1-7.

Derks, D., Bos, A. E. R., \& Von Grumbkow, J. (2008b). Emoticons in computer mediated communication: Social motives and social context. Cyber Psychology \& Behavior, 11(1), 99101.

Greenhow, C. G., Robelia, B., \& Hughes, J. (2009). Learning, teaching, and scholarship in a digital age Web 2.0 and classroom research: What path should we take now? Educational Researcher, 38(4), 246-259.

Keegan, D. (1990). Foundations of distance education. (2nd ed.). London ; New York: Routledge.

Kowitz, G. T., \& Smith, L. C. (1987). Three forms on instruction. Journal of Educational Technology Systems, 15(4), 419-429.

Lyster, R. and Ranta, L. (1997). Corrective feedback and learner uptake: Negotiation of form in communicative classrooms. Studies in Second Language Acquisition, 9, 37-66.

Perrin, D. (1999) Level of interactivity on the Internet and the Web. Retrieved January 23rd, 2003, from http://www.wsdla.org/html/journal/APR99_Issue/16 ed_apr 99c.htm

Sales, G. C. (1993). Adapted and adaptive feedback in technology-based instruction. In J. V. Dempsey \& G. C. Sales (Eds.), Interactive instruction and feedback (pp. 159-175). Englewood Cliffs, N.J.: Educational Technology Publications.

Stockwell, G., \& Hubbard, P. (2013). Some emerging principles for mobile-assisted language learning. Monterey, CA: The International Research Foundation for English Language Education. Retrieved from http://www.tirfonline.org/english-in-the-workforce/mobileassisted-language-learning

Yedla, S. (2013), MALL (Mobile Assisted Language Learning): A paradise for English language learners. International Journal of English Language \& Translation Studies, 1(2), 91-99. 